\title{
Corticofugal Output from the Primary Somatosensory Cortex Selectively Modulates Innocuous and Noxious Inputs in the Rat Spinothalamic System
}

\author{
Lénaïc Monconduit, Alberto Lopez-Avila, Jean-Louis Molat, Maryse Chalus, and Luis Villanueva \\ Institut National de la Santé et de la Recherche Médicale, E-216, Université de Clermont-1, 63000 Clermont-Ferrand, France
}

\begin{abstract}
Sensory maps for pain can be modified by deafferentation or injury, and such plasticity has been attributed mainly to changes in the convergence of projections in "bottom-up" mechanisms. We addressed the possible contribution of "top-down" mechanisms by investigating the functional significance of corticofugal influences from the primary somatosensory cortex (S1) to the ventroposterolateral thalamic nucleus (VPL). The strong convergence of spinal and lemniscal afferents to the VPL and the close correspondence between afferents and efferents within the VPL-S1 network suggest the existence of functionally related thalamocortical circuits that are implicated in the detection of innocuous and noxious inputs. Functional characterization of single nociceptive, wide dynamic range, and non-nociceptive VPL neurons and labeling the axons and terminal fields with the juxtacellular technique showed that all three types of cells project to a restricted area, within S1. The convergence of the terminal trees of axons from VPL neurons activated by innocuous, noxious, or both inputs suggests that their inputs are not segregated into anatomically distinct regions. Microinjections within S1 were performed for pharmacological manipulation of corticofugal modulation. Glutamatergic activation of corticofugal output enhanced

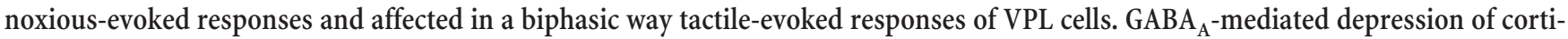
cofugal output concomitantly depressed noxious and enhanced innocuous-evoked responses of VPL neurons. Microinjections of a $\mathrm{GABA}_{\mathrm{A}}$ antagonist on corticofugal cells enhanced noxious-evoked responses of VPL cells. Our findings demonstrate that corticofugal influences from $\mathrm{S} 1$ contribute to selectively modulate somatosensory submodalities at the thalamic level.
\end{abstract}

Key words: ventrobasal thalamus; pain; allodynia; GABA; deafferentation; nociception

\section{Introduction}

Anatomical, physiological, and clinical data implicate several cortical regions in pain perception, but their precise roles in pain processing remain poorly understood. This is especially the case for the primary somatosensory cortex (S1). Although it has been proposed that S1 plays a major role in the localization and discrimination of pain, this is still a matter of controversy (Bushnell et al., 1999; Willis et al., 2002; Craig, 2003; Duncan and Albanese, 2003). A powerful endogenous control of nociception probably originates from $\mathrm{S} 1$ because cortical activity must be highly dependent on reciprocal interactions with thalamic relays, as there are nearly 10 times as many fibers projecting back from S1 to the ventrobasal thalamus as there are in the forward direction from thalamus to cortex (Liu et al., 1995; Deschênes et al., 1998; Jones, 2002; Salt, 2002). The rat ventrobasal thalamus contains only excitatory neurons that project mainly to layer IV of the S1 cor-

Received 0ct. 20, 2005; revised June 21, 2006; accepted July 1, 2006.

This work was supported by Fondation pour la Recherche Médicale, Fonds Benoît, Institut UPSA de la Douleur, and Societé Française d'Etude et de Traitement de la Douleur. We are grateful to Dr. S. W. Cadden for advice in the preparation of this manuscript.

Correspondence should be addressed to Luis Villanueva, Institut National de la Santé et de la Recherche Médicale, E-216, Université de Clermont-1, 11 Boulevard Charles de Gaulle, 63000 Clermont-Ferrand, France. E-mail: luis.villanueva@u-clermont1.fr.

DOI:10.1523/JNEUROSCI.1293-06.2006

Copyright $\odot 2006$ Society for Neuroscience $\quad$ 0270-6474/06/268441-10\$15.00/0 tex. Descending projections in the thalamocortical loop originate primarily in layers V-VI of the S1 cortex (Deschênes et al., 1998; Jones, 2002). Distal dendrites are densely innervated by these projections, which activate both ionotropic and metabotropic glutamate receptors (Jones, 2002; Salt, 2002). The function of this massive feedback network in pain has not been fully studied. However, the influence of cortical modulation from S1 on the organization of whisker-barrel receptive fields in the ventroposteromedial thalamic nucleus (Krupa et al., 1999; Ghazanfar et al., 2001; Temereanca and Simons, 2004) and on the organization of limb tactile receptive fields in the ventroposterolateral nucleus (VPL) (Yuan et al., 1986; Ghosh et al., 1994; Ergenzinger et al., 1998) has been clearly established. As in the visual and auditory systems, corticofugal influences from S1 serves to amplify the effects of sensory stimulation to the classical center-surround receptive fields and helps to sharpen and adjust the profile of thalamic receptive fields (the "egocentric selection") (Rauschecker, 1998; Suga and Ma, 2003).

Although numerous findings indicate a substantial influence of $\mathrm{S} 1$ on the processing of tactile information at a thalamic level, there has been no definitive demonstration of a major influence of $\mathrm{S} 1$ on the response properties to noxious inputs to the VPL thalamic nucleus, which is a major nociceptive relay in the spinothalamic system of the rat (Albe-Fessard et al., 1985; Guilbaud, 1985; Gauriau and Bernard, 2004; Zhang et al., 2006). 
We first examined the fine anatomo-functional organization of the VPL-S1 network by combining electrophysiological and high-resolution anatomical tracing. Based on these data, in an additional series of experiments, microinjections within the S1 area at the origin of cortico-VPL afferents were performed to investigate whether top-down influences from the S1 cortex modulate VPL cutaneous inputs. Simultaneous extracellular recordings in S1 and VPL were performed, and corticofugal output was enhanced or depressed after GABAergic or glutamatergic manipulations.

Parts of this work have been published previously in abstract form (Monconduit et al., 2005).

\section{Materials and Methods}

General. A total of 72 male Sprague Dawley rats (Charles River, SaintAubin les Elbeuf, France) weighing 220-250 g were used in this study. All animal experiments were approved by our local animal care committee and were in accordance with the guidelines of the International Association for the Study of Pain (Zimmermann, 1983).

In vivo single-cell tracing and electrophysiological characterization in the $V P L$. The rats were deeply anesthetized with $2 \%$ halothane in a nitrous oxide/oxygen mixture (2:1). To avoid oropharynx inflammation and edema, corticoids (dexamethasone phosphate, $4 \mathrm{mg} / \mathrm{kg}$; Merck Sharp and Dohme, Paris, France) were administered by intramuscular injection before the intubation. Endotracheal intubation was performed by inserting a guide wire and a catheter under direct vision with an otoscope in the oropharynx (Weksler et al., 1994). The animals were artificially ventilated at a rate of $52 \mathrm{strokes} / \mathrm{min}$. The stroke volume was adjusted to maintain a normal acid-base equilibrium as assessed with a capnometer (Capnomac II; Datex Instruments, Helsinki, Finland), which continuously measured inspired and expired $\mathrm{CO}_{2}$ (end-tidal $3.5-4.5 \%$ range), $\mathrm{O}_{2}(33 \%), \mathrm{N}_{2} \mathrm{O}(66 \%)$, and halothane levels via the catheter in the tracheal space. The animals were mounted in a stereotaxic frame. The brain was exposed by a small craniectomy, and the dura mater was removed to allow access to the thalamus. After surgery, the level of halothane was reduced to $0.7-0.8 \%$. Core temperature was maintained at $37 \pm 0.5^{\circ} \mathrm{C}$ by means of a homeothermic blanket system. Unitary juxtacellular recordings were made using glass micropipette electrodes (tip diameter, $1 \mu \mathrm{m}$; impedance, 20-30 M $\Omega$ ) filled with a $1.5 \%$ solution of 3000 molecular weight biotin-dextran (BD) (Invitrogen, Carlsbad, CA) diluted in 3\% $\mathrm{NaCl}$. After amplification, the signals were fed into a window discriminator and observed on an oscilloscope. Single-unit activity was digitized and monitored on-line using a data acquisition system (CED 1401 with Spike 2 software; Cambridge Electronics Design, Cambridge, UK). A systematic search was performed for units responding to cutaneous tactile and/or noxious thermal stimulation of the contralateral hindpaw. Once a VPL neuron was characterized, it was individually labeled by juxtacellular iontophoresis of $\mathrm{BD}$, using the technique developed by Pinault (1996) that combines the functional characterization of extracellularly recorded VPL neurons and the staining, in a Golgi-like manner, of their perikarya, dendritic, and axonal fields.

The bridge circuitry of the recording amplifier (Axoclamp 2B; Molecular Devices, Palo Alto, CA) was used to apply the tracer with low intensity ( $<10 \mathrm{nA})$ positive-current pulses (200 ms on/200 ms off), which continued to elicit regular firing from the unit for 5-40 $\mathrm{min}$.

At the conclusion of the iontophoresis, the surgical wounds were sutured and disinfected. The level of anesthesia was progressively reduced, and, once spontaneous breathing could be observed, the tracheal tubes were removed. Each animal was kept in an individual cage, and, after a postoperative survival of $2-3 \mathrm{~d}$, the animals were reanesthetized with an overdose of chloral hydrate $(800 \mathrm{mg} / \mathrm{kg}$, i.p. $)$ and perfused over a $20 \mathrm{~min}$ period, with $200 \mathrm{ml}$ of warm $\left(37^{\circ} \mathrm{C}\right)$ heparinized PBS, followed by 1000 $\mathrm{ml}$ of a phosphate-buffered solution $(0.1 \mathrm{M}), \mathrm{pH} 7.4$, containing $4 \%$ paraformaldehyde, $0.1 \%$ glutaraldehyde, and $0.05 \%$ picric acid. The brain was removed and then cryoprotected in a buffered 30\% sucrose solution. Two days later, $80-\mu \mathrm{m}$-thick coronal sections were cut on a freezing microtome, rinsed several times with PBS (0.1 M), $\mathrm{pH} 7.4$, and processed for BD histochemistry. After rinsing for $20 \mathrm{~min}$ with PBS, the sections were placed in the avidin-biotin-HRP complex solution at the recommended dilution in PBS for $1 \mathrm{~h}$. The sections were then rinsed for 15-20 min with PBS and incubated for $2 \mathrm{~min}$ in a Tris-buffered solution containing $0.05 \% \mathrm{DAB}$ and $0.2 \%$ ammonium nickel sulfate (Sigma, St. Louis, MO). Increasing doses of $\mathrm{H}_{2} \mathrm{O}_{2}$ were added every $5 \mathrm{~min}$ to the DAB solution to obtain $\mathrm{H}_{2} \mathrm{O}_{2}$ concentrations of $0.05,0.1,0.2,0.5$, and $1.0 \%$. The reaction was stopped by a $10 \mathrm{~min}$ rinse in Tris buffer.

Analysis of the histological data. After a postoperative survival of 2-3 d, the animals were perfused, the brain was removed and processed for BD histochemistry (Monconduit and Villanueva, 2005). Digitized grayscale images were built using a computer-assisted reconstruction of BD labeling technique described in detail previously (Villanueva and Le Bars, 1993). Fully labeled neurons were reconstructed from superimposed camera lucida drawings of a large series of adjacent coronal $80-\mu \mathrm{m}$-thick sections. Superimposition of two digitized planes was made in Photoshop 5 (Adobe Systems, San Jose, CA) using translation and rotation until the main landmarks [border of section, blood vessels, mammillothalamic tract, and medial lemniscus (Paxinos and Watson, 1997)] fit adequately; the next step was a search for a more precise correspondence between dendrite elements. Morphometric analyses using VisionStage IP software (Alliance Vision 1.6) measured (1) the diameter of the soma, and (2) the diameters of the whole dendritic domain. We also examined the shape of the soma, the dendritic tree, the number of poles, and their general direction (main axis). Branching asymmetry for each labeled cell was calculated by measuring the distribution of the dendritic tree in a two-dimensional projection of the neuron in the coronal plane. A circle was defined and divided into six areas of $30^{\circ}$ each. The orientation angles were defined with respect to a horizontal mediolateral line through the center of the soma. This $x$-axis was defined with regard to the main landmarks (border of section, blood vessel, mammillothalamic tract, and medial lemniscus). The length of each dendrite was calculated within each $30^{\circ}$ area and was expressed as a percentage of the total length of the dendrites (see Fig. $1 B$ ).

Electrophoretic injections of tetramethylrhodamine labeled-dextran into the VPL. The rats were anesthetized with chloral hydrate $(400 \mathrm{mg} / \mathrm{kg}$, i.p.) and then mounted in a stereotaxic device, and a craniotomy was performed. Glass micropipettes (5-10 mm diameter tips) filled with a $10 \%$ solution of tetramethylrhodamine labeled-dextran (TMR), 3000 molecular weight, lysine fixable (Invitrogen), were positioned on the VPL. Multiunit electrophysiological recordings of cells responding to tactile and noxious heat stimulation of the extremity of the hindpaw were performed. Once these cells were encountered, direct current $(2-4 \mu \mathrm{A}$; micropipette positive) was applied for $20 \mathrm{~s}$ every $30 \mathrm{~s}$ for $5 \mathrm{~min}$. After a postoperative survival period of 2 weeks, the animals were reanesthetized and perfused over a $20 \mathrm{~min}$ period with $200 \mathrm{ml}$ of warm $\left(37^{\circ} \mathrm{C}\right)$ heparinized PBS, followed by $1000 \mathrm{ml}$ of a phosphate-buffered solution $(0.1 \mathrm{M})$, pH 7.4, containing 4\% paraformaldehyde. The brain and spinal cord were removed and soaked in the latter solution for several hours and then cryoprotected in a buffered $30 \%$ sucrose solution. Two days later, the $40-\mu \mathrm{m}$-thick coronal sections were rinsed several times with PBS $(0.1 \mathrm{M})$, $\mathrm{pH}$ 7.4. The sections were divided into two groups. The sections were incubated for 2-4 h in PBS containing $0.4 \%$ Triton X-100 and $2 \%$ normal goat serum (NGS). They were then incubated overnight in the primary antiserum, namely 1:6000 rabbit anti-dextran (Invitrogen), in PBS containing $0.4 \%$ Triton X-100 and 2\% NGS. After 20 min rinsing with $\mathrm{PBS}$, the sections were incubated for $1 \mathrm{~h}$ in the secondary antiserum, namely l:200 biotinylated anti-rabbit IgG (produced in goats; Jackson ImmunoResearch, West Grove, PA) in PBS containing 0.4\% Triton $\mathrm{X}-100$ and $2 \%$ normal rabbit serum. After 20 min rinsing with PBS, the sections were placed in the $\mathrm{ABC}$ complex solution and processed with DAB. Finally, one group was counterstained with cresyl violet.

Extracellular recordings. In rats anesthetized with halothane, multiunit recordings were obtained in layers V-VI of S1 to locate the hindpaw representation area, using low-impedance ( $400 \mathrm{k} \Omega$ to $1 \mathrm{M} \Omega$ ) stainless steel microelectrodes (World Precision Instruments, Aston, UK). Details of anesthesia and surgery were as reported previously (Monconduit et al., 1999). Multiple extracellular single units were simultaneously recorded in the VPL thalamic nucleus using quartz-insulated, platinum-tungsten microelectrodes custom ground to impedances of 2-6 M $\Omega$. The five 
electrodes were positioned $300 \mu \mathrm{m}$ apart in the rostrocaudal axis on the VPL and advanced into the brain independently using a five-channel Eckhorn mini-matrix microdrive system (Uwe Thomas Recordings, Glessen, Germany). This device allows the insertion of thin shaft probes into the neural tissue by a stretched elastic rubber tube in which the quartz-insulated, platinum-tungsten electrodes are guided (Eckhorn and Thomas, 1993). This enables smooth movements performed with independently advanceable electrodes. Moreover, the electrodes are quite thin (60 $\mu \mathrm{m}$ shaft; $10 \mu \mathrm{m}$ tip diameters) but strong enough to penetrate through the dura, thus reducing the damage to the brain tissue. Microelectrode signals were amplified, filtered, digitized, and discriminated with a personal computer-controlled multichannel neuronal acquisition processor (MNAP) (Plexon, Dallas, TX). The discrimination of spike waveforms was done using a real-time hardware-implemented combined time-voltage window discriminator, which is part of the Rasputin software package that controls the MNAP. Single spikes were discriminated by combining a principal component algorithm running in real time and one pair of time-voltage windows per unit. The size and position of the time-voltage boxes are defined by the experimenter to isolate the waveforms that belonged to a given unit. Spikes were only accepted as valid when they pass through both boxes (for more technical details, see Nicolelis et al., 1997). Raw and discriminated signals were fed through an audio monitor and displayed on an oscilloscope for additional inspection. Waveforms and recorded spike trains were stored on computer disk for off-line analyses. Poststimulus and cumulative frequency histograms (bin size, $500 \mathrm{~ms}$ ) were used to detect the occurrence of statistically significant neuronal responses and also to quantify their magnitude and thresholds for activation. OffLine Sorter (Plexon) was used for off-line sorting of digitized waveforms. Spike train analyses were performed using NeuroExplorer (Nex Technologies, Winston-Salem, NC) and Matlab (MathWorks, Natick, MA).

Intracortical administration of drugs. We tested the effects of microinjections within layer V-VI of S1 (see Fig. 2) on background and evoked cortical and thalamic neuronal responses. The drugs used were DLhomocysteic acid (DLH) (10 mM, $200 \mathrm{nl}$ dissolved in saline), muscimol ( $8.7 \mathrm{~mm}, 500 \mathrm{nl}$ dissolved in saline), and a subconvulsive dose of bicuculline ( $50 \mu \mathrm{M}, 500 \mathrm{nl}$ dissolved in saline). These substances were injected at a rate of $100 \mathrm{nl} / \mathrm{min}$ using a Hamilton microliter syringe with a tip of 170 $\mu \mathrm{m}$, driven by an electronic geared syringe pump (Micro4; World Precisions Instruments). The specificity of the effects of drugs was confirmed by the lack of effects of microinjections of $500 \mathrm{nl}$ of saline in the same cortical places $[n=6$; values of $83 \pm 21,112 \pm 37$, and $117 \pm 14 \%$ with regard to controls (100\%) were obtained 5, 15, and 30 min after saline injections] and the lack of effects of injections of GABAergic drugs placed in neighboring, somatotopically inappropriate areas of S1, namely outside from the hindpaw inputs, either deeper in the corpus callosum or more laterally (see Fig. 3). The distance between the cortical recordings and microinjections was $\sim 100 \mu \mathrm{m}$. At the conclusion of the experiments, the recording sites and microinjections were marked by deposition of pontamine sky blue. The injections sites were examined on Nissl counterstained tissue.

Hindpaw stimulation and experimental design. Calibrated brushing of the extremity of the hindpaw was performed with a computer-driven motorized, $360^{\circ}$-turning paint brush. The brushing stimuli consisted of rostrocaudally directed brushing at a frequency of $2 \mathrm{~Hz}$, for $30 \mathrm{~s}$ over a skin surface area of $\sim 40 \mathrm{~mm}^{2}$. Thermal stimuli were produced with a 13 $\mathrm{mm}^{2}$ circular thermode (Seicer, Mouy, France) whose temperature was controlled by thermoelectric Peltier elements that were driven by a computer. Tonic noxious thermal stimuli consisted in $30 \mathrm{~s} 44-55-44^{\circ} \mathrm{C}$ ramps that were applied to the extremity of the hindpaw in an area adjacent to the brushing (see Fig. $3 A$ ).

A systematic search for VPL units responding to innocuous stimulation (rubbing, gentle stroking) of the extremity of the hindpaw was used. Once the area containing neurons responding to such search stimuli was found, cortical multiunit, local field potential, and thalamic multiunit recordings were obtained after cutaneous stimulation of adjacent areas located on the extremity of the hindpaw. Once the clusters of thalamic cells responding to the extremity of the hindpaw were found and isolated, the thermode and paint brush were placed in neighboring areas within the receptive fields and fixed for the whole recording period. Three sets of control, innocuous, and noxious cutaneous stimuli were applied before cortical microinjections, with an interval of at least 15 min between any two sets. Postinjection tests were performed every 15 min for $1 \mathrm{~h}$. Mean background activity was calculated from a $200 \mathrm{~s}$ period before each test. VPL neurons showed highly variable background activity, and the level of this was subtracted from the total number of spikes observed during stimulation. Time segments of $30 \mathrm{~s}$ for innocuous and noxious thermal stimulation were used to determine differences between discharge rates. Three time segments of $10 \mathrm{~s}$ each were measured just before the starting of stimulation, before and after pharmacological manipulations. These time segments were compared with the aim to detect changes in the onset of the responses. The same procedure was applied immediately after the end of the stimulation to measure afterdischarges. Calculation of neuronal discharges was performed with NeuroExplorer and were expressed in hertz. Statistical analyses were performed using ANOVA and Student's $t$ tests. The level of significance was set at $p<0.05$. Cumulative results (means \pm SEMs) are expressed as percentage changes with regard to the mean of the total spikes from the three control responses during innocuous or noxious stimulation. We examined the difference in mean values between subgroups (muscimol vs bicuculline) using the Mann-Whitney $U$ test.

\section{Results}

Simultaneous juxtacellular recordings and biotin-dextran iontophoresis were performed in 13 VPL neurons of 31 anesthetized rats. All of the VPL neurons had receptive fields that could be activated by natural cutaneous stimulation of the paws. As in previous studies (Albe-Fessard et al., 1985; Guilbaud, 1985), the cells were classified as nociceptive specific (NS) if they were responsive only to noxious heat $\left(48^{\circ} \mathrm{C}\right)$, non-nociceptive $(\mathrm{NN})$ if they were responsive only to innocuous brushing, and widedynamic range (WDR) cells if they were responsive to both noxious heat and brushing. The receptive fields of NN cells were generally small and confined to the extremity of the limb. Although the need for rapid characterization prevented us from systematically delimiting the nociceptive receptive fields of NS and WDR cells, they were quite variable, generally large, and could be bilateral. Using this classification based on the responses to natural stimuli, four VPL neurons were categorized as NS, four as NN, and five as WDR cells (see individual examples in Fig. 1). None of the functional categories was associated with cells of a particular morphology, size, or dendritic tree. Cumulative data in Figure $1 B$ shows that most of the neurons were multipolar with dense dendritic arbors of variable length and orientations. All of the axons of NS, NN, and WDR cells turned rostrally through the internal capsule, often after giving off collaterals in the thalamic reticular nucleus (NRT). These axons then passed through the ipsilateral globus pallidus and striatum, the corpus callosum, the forceps minor, and terminated mainly within layer IV of the primary somatosensory cortex. Terminal labeling was in the form of thin collateral fibers that innervated a common area of S1 between bregma -1.2 and -0.7 (Paxinos and Watson, 1997). Small varicosities within layer IV extended for $260 \pm 136,227 \pm 94$, and $229 \pm 134 \mu \mathrm{m}$ in the rostrocaudal axis for NS, NN, and WDR cells, respectively.

To determine precisely the thalamocortical recipient zones of lemniscal and spinal inputs from the hindpaw, we made small iontophoretic injections of the high-resolution anterograde/retrograde tracer TMR into the VPL in five rats. Injections were performed under electrophysiological control with the aim of labeling the VPL area containing the neurons activated by innocuous and noxious cutaneous inputs from the hindpaw. Injections of TMR into the physiologically defined area of the VPL (Fig. 2A) produced dense labeling of efferents that terminated mainly as 
patches in layer IV of the rostral S1 cortex and extended superficially to layer III (Fig. $2 B$ ). Figure $2 C$ shows, at high magnification, a reconstruction of labeling in $\mathrm{S} 1$ in the form of a dense network of thin afferent fibers with small varicosities in the centralmost aspect of layer IV. Moreover, numerous retrogradely labeled neurons with apical dendrites were observed in layer VI. These corticothalamic cells occupied the same area as that covered by the band of afferent labeling in layer IV. The most dense labeling was between bregma -1.3 and 0.8 (Paxinos and Watson, 1997), and it diminished progressively in both caudal and rostral directions. Interestingly, the densest labeling was located in the same S1 zone that contained the afferents of physiologically identified neurons as shown in Figure 1. In the areas containing less anterograde labeling, it was possible to see that apical dendrites of corticothalamic cells had terminal arbors within layer IV. The cortices that contained the most dense VPL projections also contained the largest number of retrogradely labeled cells in the deep layers, and these showed a distribution that paralleled that of the layer IV thalamic projections.

To study the effects of corticofugal modulation of VPL responses to somatosensory stimuli, we examined corticofugal effects on calibrated, innocuous mechanical (brushing) and noxious heat-evoked responses of VPL cells in 36 rats. Simultaneous, extracellular recordings of the responses of VPL neurons and multiunit recordings of layer V-VI of S1 after innocuous and noxious cutaneous stimulation of neighboring areas on the hindpaw were performed (Fig. 3A). Corticofugal activity was depressed or enhanced after microinjections of $\mathrm{GABA}_{\mathrm{A}}$ agonists and antagonists in the layer V-VI zone that innervates VPL neurons driven from receptive fields on the hindpaw (Fig. $3 B$ ). Microinjections of the $\mathrm{GABA}_{\mathrm{A}}$ agonist muscimol strongly reduced cortical activity in deep layers of S1 by $46 \pm 27 \%, 15$ min after the injection. Concomitantly, brushing-evoked responses were enhanced and noxious heat-evoked responses of VPL neurons were depressed (Fig. 4). As shown in the individual examples, the dual effects of muscimol on innocuous and noxious cutaneous responses were observed in all of the neuronal types recorded in the VPL. Although in some individual cases (Fig. 4, $\mathrm{NN}$ neuron) we observed either increases in background activities or afterdischarges, cumulative results showed that the thresholds for activation and back-
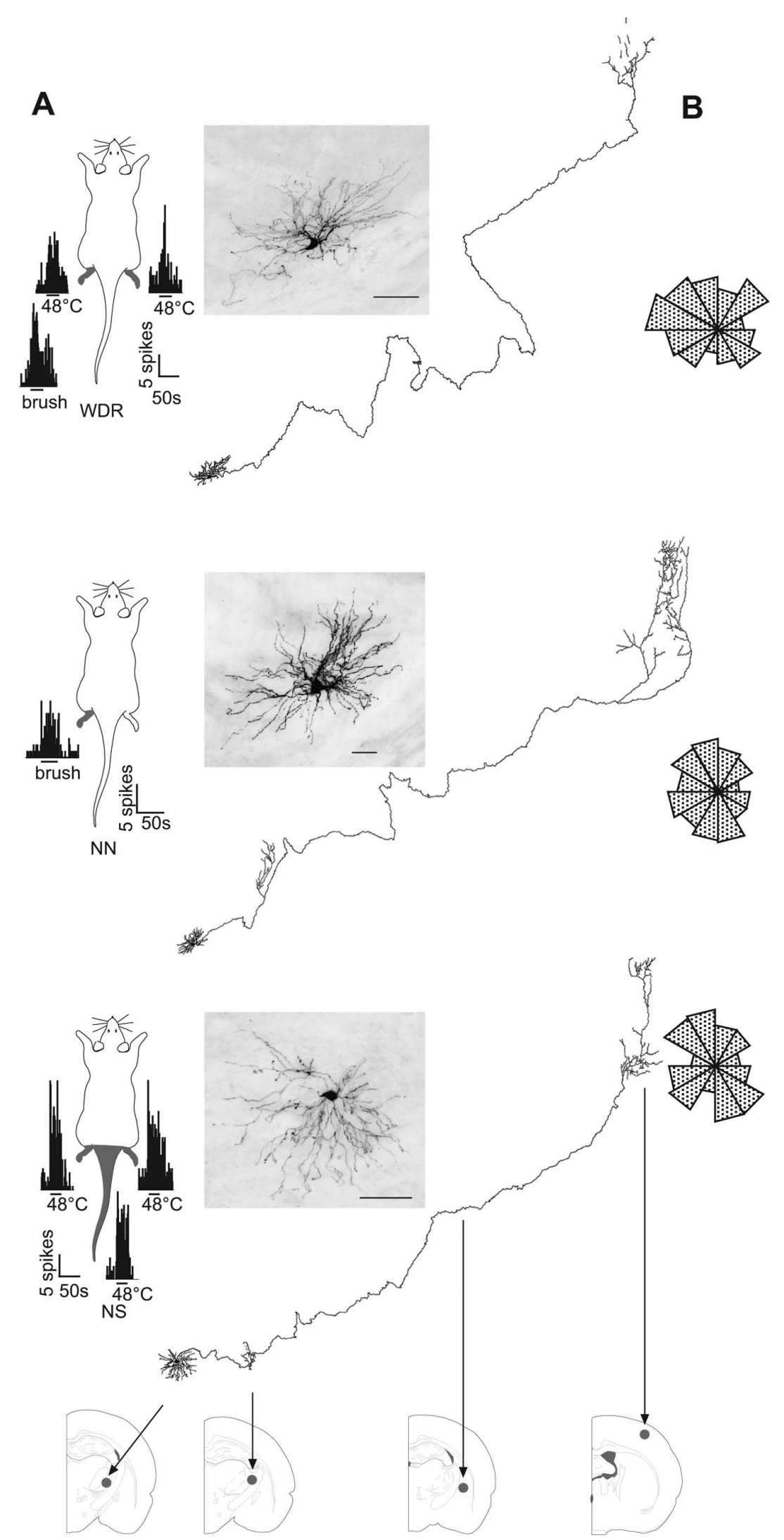

Figure 1. A, Digital photomicrographs of the perikaryon and proximal processes of three different functional classes of juxtacellularly stained VPL neurons (NS, NN, and WDR). For each cell, the response characteristics to peripheral cutaneous stimuli and the receptive fields are presented. Camera lucida drawings of cells with their axonal processes and terminal innervation in a common area within S1. Scale bars, $50 \mu \mathrm{m}$. B, Cumulative data showing the topographic distribution of dendritic arbors of juxtacellularly labeled VPL cells. Areas representing percentage of the total length of the dendrites within $30^{\circ}$ sections show the widespread, multipolar orientation of the dendritic trees. 


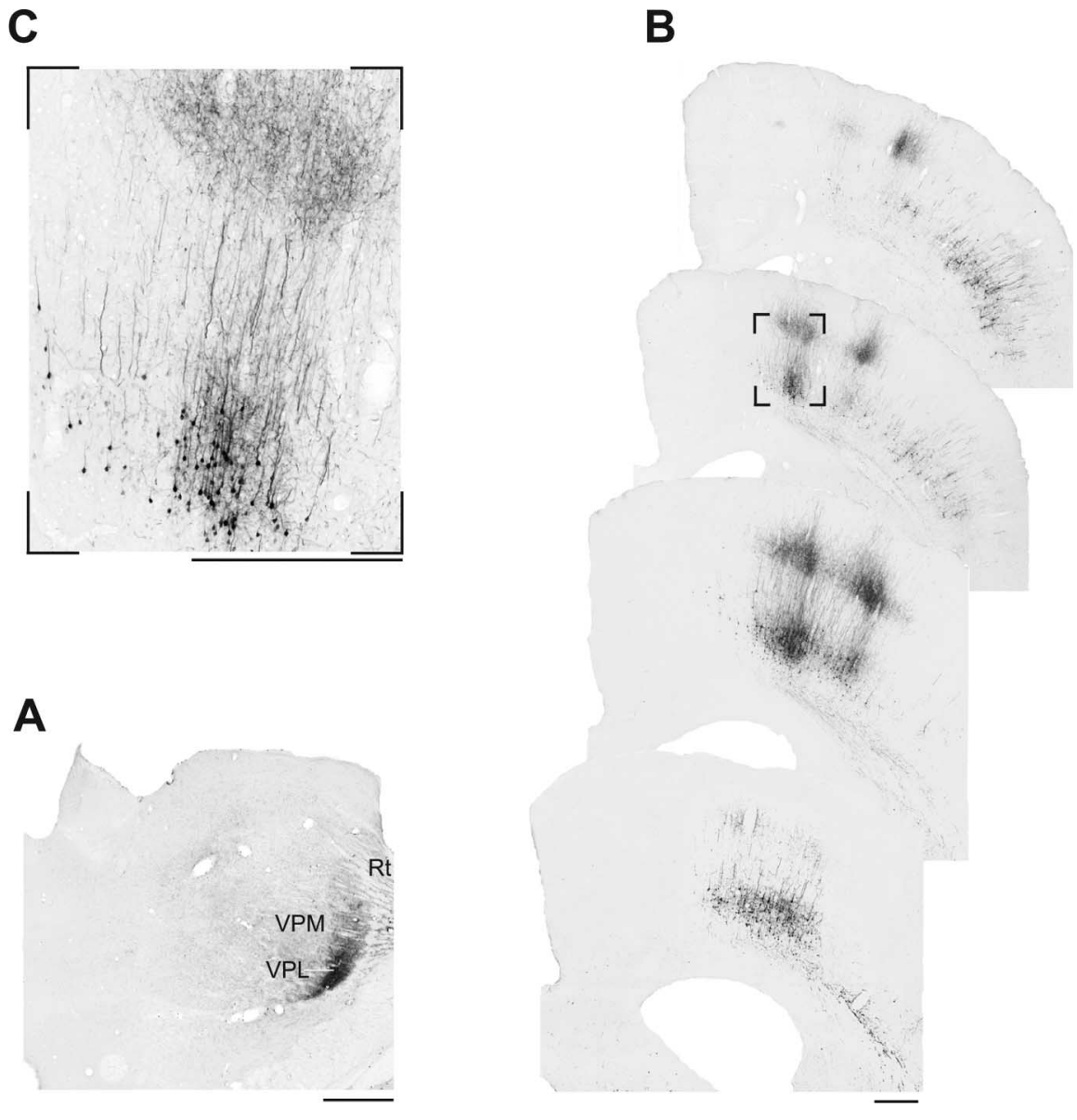

Figure 2. Digital photomicrographs of labeling in coronal sections of the S1 cortex (B) after the tetramethylrhodamine-labeled dextran injection into the VPL thalamic nucleus shown in $\boldsymbol{A}$. C shows higher magnification of the layer IV afferent labeling from the VPL and layer VI efferent labeling in the region delineated in $\boldsymbol{B}$. Note the numerous retrogradely labeled cells in layer VI, which occupy the same area covered by the patches of anterograde labeling in layer IV. Scale bars, $500 \mathrm{~mm}$. Rt, Thalamic reticular nucleus; VPM, ventroposteromedial thalamic nucleus.

ground activities of VPL cells were not significantly affected by muscimol.

Microinjections of the $\mathrm{GABA}_{\mathrm{A}}$ antagonist bicuculline did not elicit significant enhancement of background or cutaneous evoked activities in layers V-VI but enhanced noxious heatevoked responses of WDR and NS thalamic neurons (Fig. 5). Cumulative results (Fig. 6, Table 1) showed that significant effects were obtained $15 \mathrm{~min}$ after an injection with a volume of 500 $\mathrm{nl}$ of muscimol. Innocuous-evoked responses of NN $(n=21)$ and WDR $(n=22)$ cells were enhanced by $68 \pm 47$ and $45 \pm$ $42 \%$, respectively $(p<0.05$ ), and lasted throughout the $60 \mathrm{~min}$ postinjection control period. Cortical activity did not recover after muscimol injections. Concurrently, muscimol significantly depressed noxious heat-evoked responses of NS $(n=14)$ and WDR cells by $73 \pm 12$ and $37 \pm 24 \%$, respectively $(p<0.05)$. Bicuculline enhanced noxious heat-evoked responses of NS $(n=$ $10)$ and WDR $(n=37)$ cells without affecting innocuous-evoked responses of $\mathrm{NN}(n=11)$ and WDR neurons. After a $500 \mathrm{nl}$ bicuculline injection, noxious heat-evoked responses of NS and WDR cells were enhanced by $91 \pm 73$ and $54 \pm 17 \%$, respectively $(p<0.05)$. This enhancement was significant $5 \mathrm{~min}$ after bicuculline and lasted for $\sim 15 \mathrm{~min}$. Nonparametric analysis of the noxious-evoked responses of WDR and NS neurons showed a significant difference between the effects of muscimol versus bicuculline $(p<0.005)$. The background activity and thresholds for peripheral activation of VPL neurons were not significantly affected by either muscimol or bicuculline. Background activity was $2.9 \pm 0.6 \mathrm{~Hz}$ for controls, then $3.2 \pm 0.6,3.1 \pm 0.5$, and $3.4 \pm 0.5 \mathrm{~Hz}$ at 5 , 15 , and $30 \mathrm{~min}$ after bicuculline and $7.1 \pm$ $0.8 \mathrm{~Hz}$ for controls, and then $7.2 \pm 0.8$, $7.3 \pm 0.9$, and $7.8 \pm 1 \mathrm{~Hz}$ at 5,15 , and 30 min after muscimol. Afterdischarges were $5.9 \pm 3 \mathrm{~Hz}$ before and $1 \pm 2.6,1.6 \pm 2$, and $1 \pm 2.7 \mathrm{~Hz}$ at 5,15 and $30 \mathrm{~min}$ after bicuculline respectively, and $5.5 \pm 5.2 \mathrm{~Hz}$ before and $2.4 \pm 8.2,1.4 \pm 2.9$, and $4.6 \pm 3.2$ $\mathrm{Hz}$ at 5,15 , and $30 \mathrm{~min}$ after muscimol, respectively. In fact, afterdischarges, when present, usually occurred also during the control tests. Also, we did not find significant changes in the onset of both tactile and noxious-evoked responses after microinjections.

In a last series of experiments, we tested the effects of a direct, glutamatergic activation of corticothalamic output after microinjections of the excitatory amino acid DLH into layers V-VI. Concomitantly, noxious-evoked responses of both WDR and NS and responses of NN cells were enhanced (125 \pm 46, $80 \pm 26$, and $107 \pm$ $70 \%$, respectively). Innocuous-evoked responses of WDR were affected in a biphasic way, namely a depression $(75 \pm 16 \%)$, followed by a facilitation $(90 \pm 44 \%)$. As shown in the cumulative data in Figure 6, the effects of DLH were significant between 5 and 30 min after microinjection.

As a whole, our data showed that muscimol depressed noxious-evoked responses in $63 \%$ of WDR or NS neurons, $15 \%$ were facilitated, and $22 \%$ were unaffected. Concerning innocuous-evoked responses, muscimol facilitated 58\% of NN and WDR cells, 25\% were depressed, and 17\% were unaffected. Bicuculline facilitated noxious-evoked responses of $72 \%$ of WDR or NS neurons, $23 \%$ were depressed, and 5\% were unaffected. DLH facilitated noxious-evoked activities of $62 \%$ of WDR and $57 \%$ of NS cells and depressed $33 \%$ of WDR and $37 \%$ of NS cells. A lack of effect of DLH was observed in 5\% and 6\% of WDR and NS cells, respectively. DLH depressed $80 \%$ and then facilitated $70 \%$ of innocuous-evoked responses of WDR cells. DLH facilitated all of the NN cells recorded. Similar trends of effects were observed in the different cell classes in each individual animal.

Cumulative data of blood pressure monitoring after the application of noxious thermal stimuli showed mean arterial blood pressure $(109 \pm 5 \mathrm{mmHg})$ increases of $22 \pm 5,18 \pm 5$, and $15 \pm$ $4 \%$ above the control values for the three controls before microinjections. Such increases started at stimulation temperatures of $49 \pm 0.5^{\circ} \mathrm{C}$ and were not modified by any of the cortical microinjections.

No significant differences in spike amplitude during the whole recording period were observed after measurements of VPL cells with Spike 2 software. Cumulative data showed spikes amplitudes of $3.0 \pm 0.8,3.1 \pm 0.9$, and $2.9 \pm 0.7 \mathrm{~V}$ before, during, and after noxious thermal stimulations. 
A
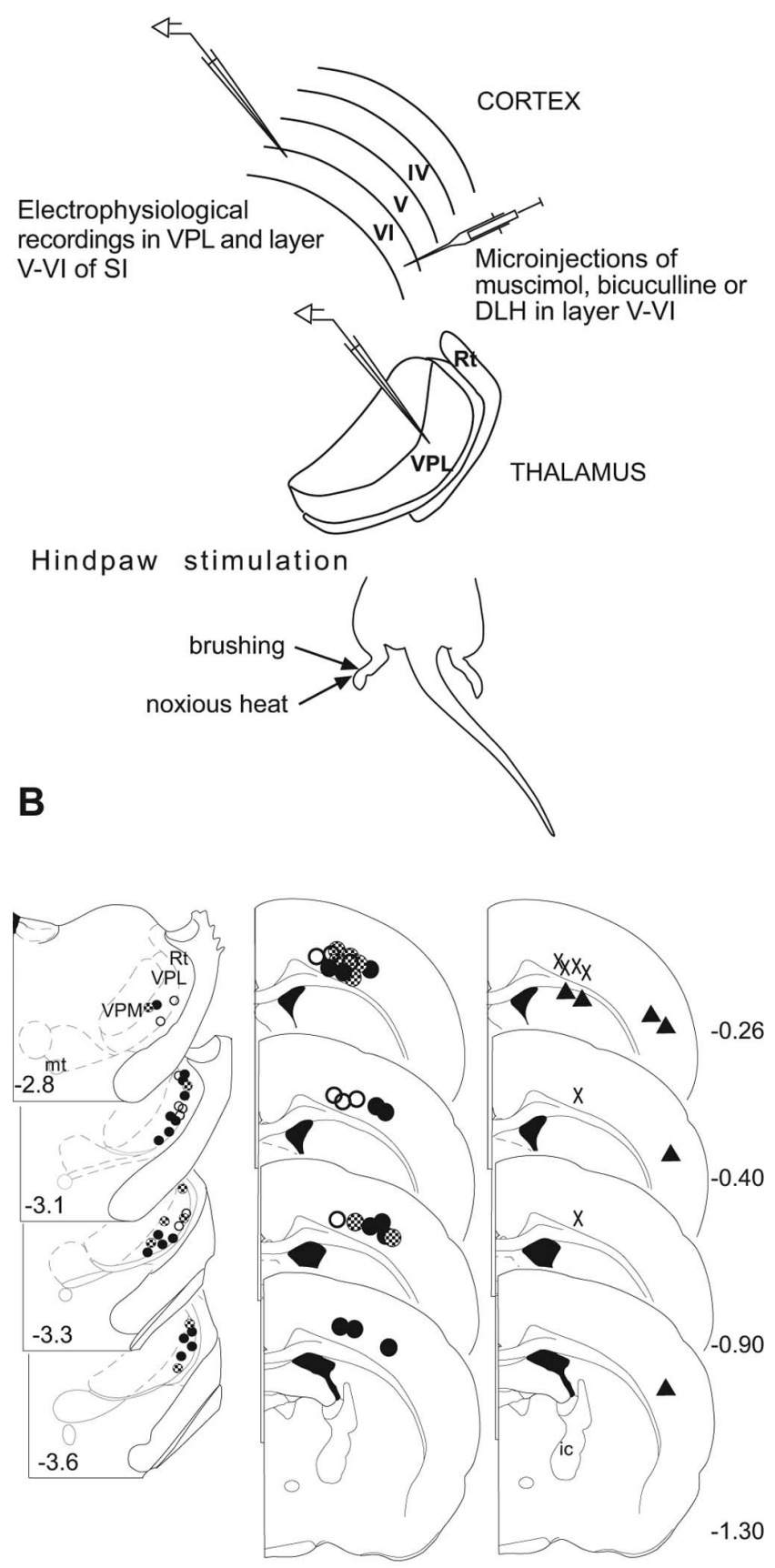

\section{- muscimol \\ bicuculline \\ ODLH}

$x$ controls

$\Delta$ negative results

Figure 3. A, Experimental setup for the multiunit, multisite recordings and cortical microinjections. $\boldsymbol{B}$, Summary of the histological findings from experiments during which the effects on the responses of VPL neurons of microinjections of $G A B A_{A}$ agonists or antagonists, the glutamate agonist DLH, and saline in layer V-VI of the $\mathrm{S} 1$ cortex were studied. Negative results were obtained with microinjections of muscimol or bicuculline. Location of the injection sites in S1 and rostrocaudal distribution of recordings in the VPL. Numbers indicate distance with respect to bregma. Rt, Thalamic reticular nucleus; VPM, ventroposteromedial thalamic nucleus.

\section{Discussion}

Our results and previous studies (Peschanski et al., 1984; Harris, 1986) showed a lack of correlation between somatodendritic structure and function in either modality-selective or modality-
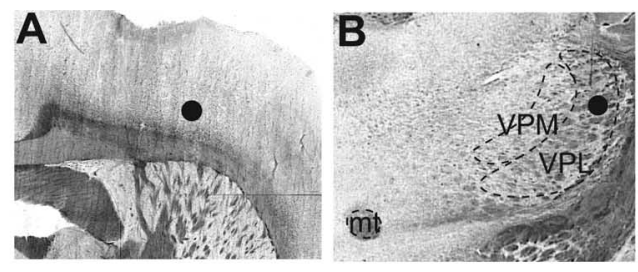

Control
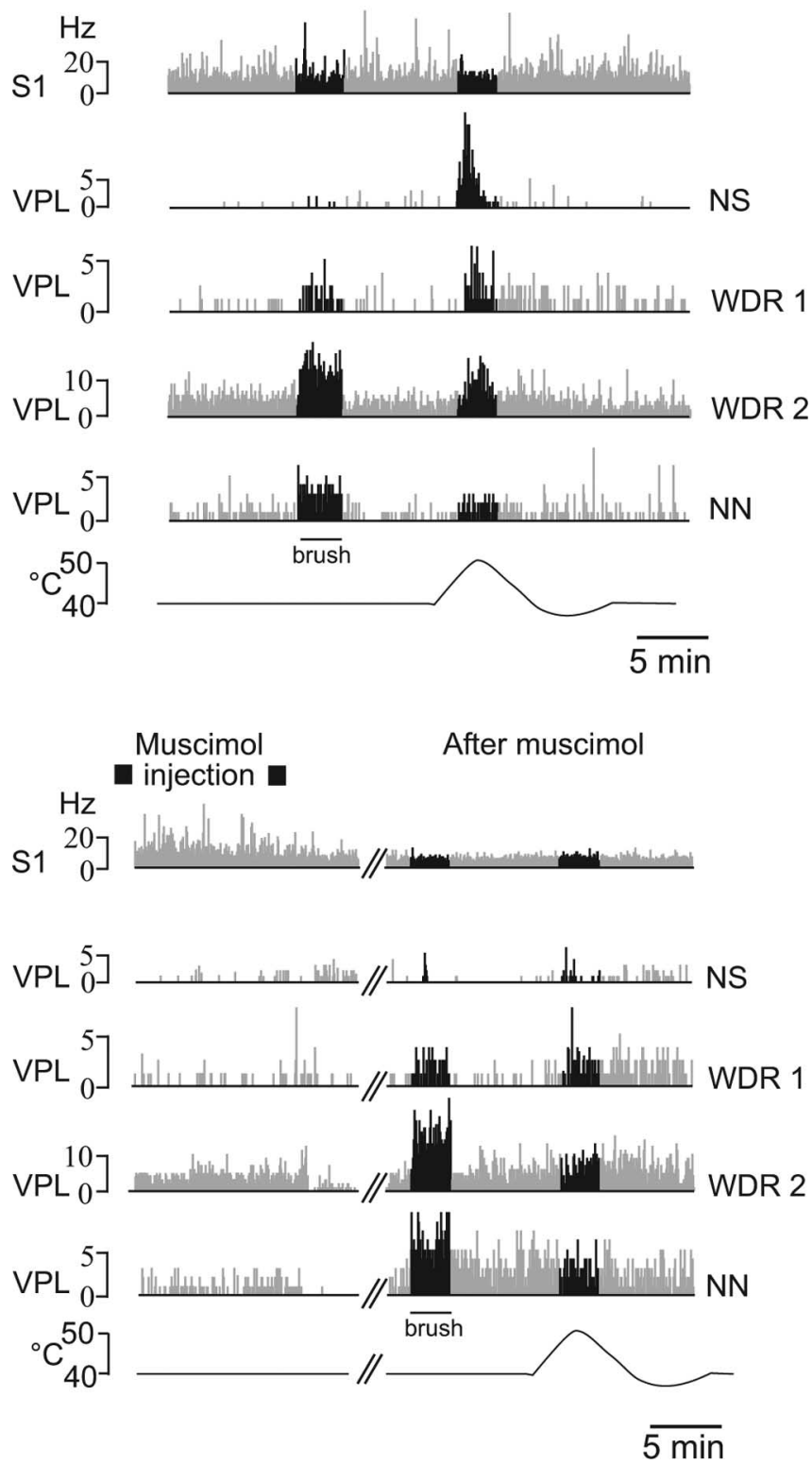

Figure 4. Examples of the effects of a microinjection of muscimol $(8.7 \mathrm{~mm}, 500 \mathrm{nl})$ into layer $\mathrm{V}-\mathrm{VI}$ of the $\mathrm{S1}$ cortex $(\boldsymbol{A})$ on the responses of four neurons simultaneously recorded in the VPL (B). The stimuli were brushing or noxious heat ramps applied to the extremity of the hindpaw. Note that cortical activity was depressed by the microinjection, whereas innocuous-evoked responses were enhanced (17, 37, and 56\% for WDR 1, WDR 2, and NN, respectively) and noxious-evoked responses were depressed ( 94,29 , and 42\% for NS, WDR 1, and WDR 2, respectively) in the VPL. mt, Mammillothalamic tract; VPM, ventroposteromedial thalamic nucleus.

nonselective VPL neurons. The rat VPL appears to contain mainly one major, multipolar cell type that processes all submodalities of somatosensory information (Fig. 1). This is also in agreement with data from monkey studies showing similar so- 

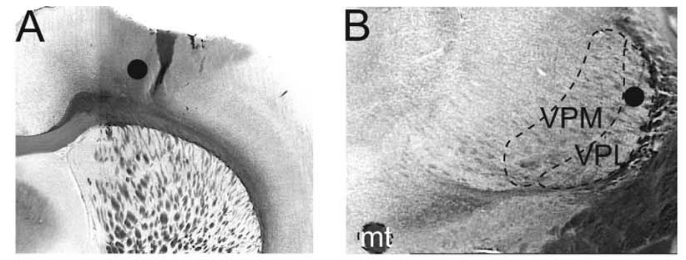

Control
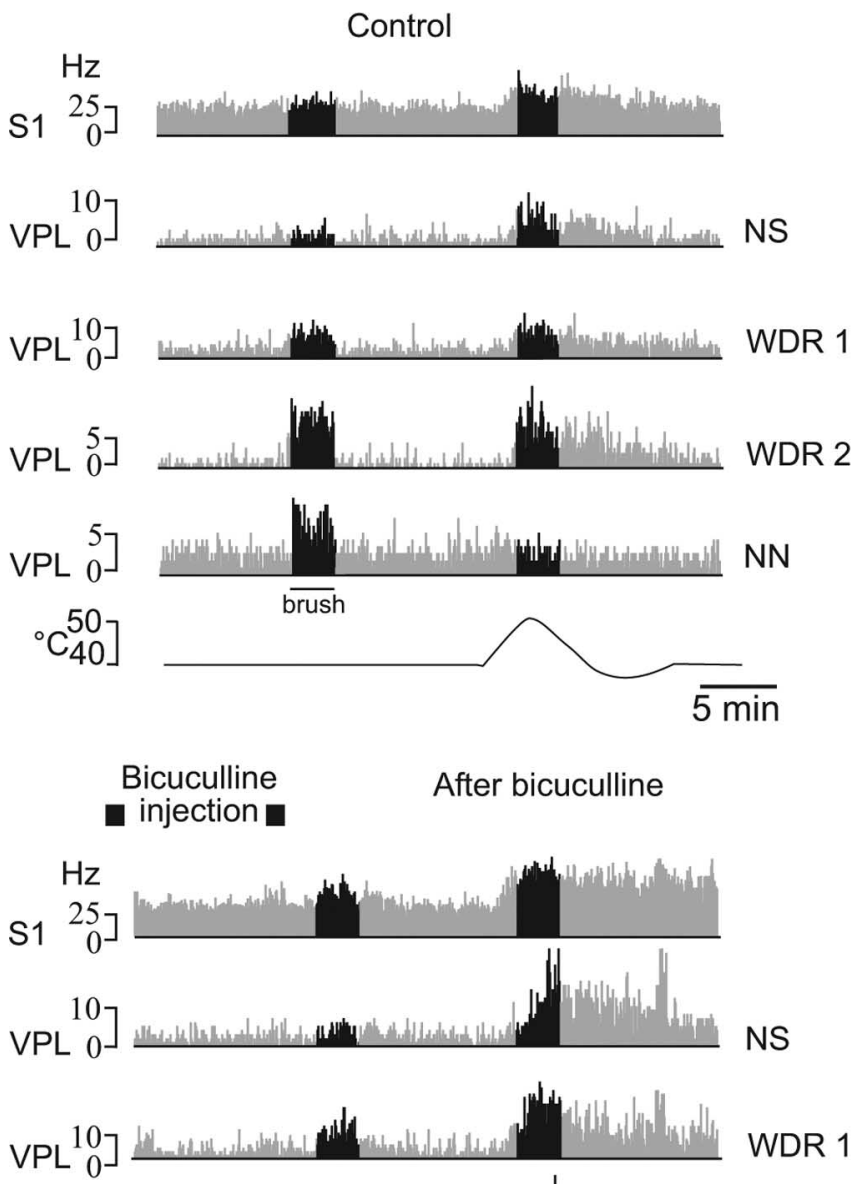

WDR 1

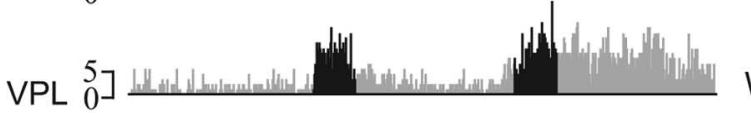

WDR 2

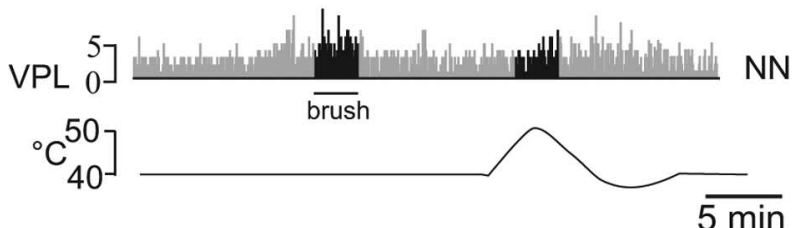

Figure 5. Examples of the effects of a microinjection of bicuculline $(50 \mathrm{~mm}, 500 \mathrm{nl})$ into layer $\mathrm{V}-\mathrm{VI}$ of the $\mathrm{S} 1$ cortex $(\boldsymbol{A})$ on the responses of four neurons simultaneously recorded in the VPL (B). The stimuli were brushing or noxious heat ramps applied to the extremity of the hindpaw. Note that noxious-evoked responses in the VPL were enhanced (59, 72, and 11\% for NS, WDR 1 , and WDR 2, respectively), whereas innocuous-evoked thalamic responses were unaffected. $\mathrm{mt}$, Mammillothalamic tract; VPM, ventroposteromedial thalamic nucleus.

matic and dendritic morphologies of S1-projecting neurons in several thalamic nuclei (Shi and Apkarian, 1995).

The juxtacellular technique allowed labeling the axons and terminal fields of the three functional classes of VPL neurons showing that all cells project to a restricted area within S1. Although we confirmed that this technique allows the labeling of only a single thalamic neuron with current pulses provided that the iontophoretic currents caused it to fire (Pinault, 1996), its main limitation originates from its variability. We did not find a direct relationship between the duration of the juxtacellular injection and the amount of labeling. It was sometimes possible to label a neuron and its terminal tree after relatively short-duration current applications ( $\sim 5 \mathrm{~min})$, whereas in other cases, only the perikaryon and proximal processes were labeled after injections times as long as $30 \mathrm{~min}$. Despite its variability, this technique produces a good success rate for labeling a large number of neurons (Pinault, 1996; Pilowsky and Makeham, 2001). However, the amount and frequency of labeling depend on the thalamic area from which recordings are made. For instance, the success rate is significantly higher after recordings in VPL than ventromedial (VM) cells (Monconduit and Villanueva, 2005) because VPL cell bodies are sizable, in contrast to the narrow, fusiform shape of VM cell bodies and their thinner, longer axonal processes.

Although our sample is too small because of the difficulties to obtain a larger number of cells with labeling of their axonal terminal fields, the convergence of the terminal trees of axons from VPL neurons activated by innocuous, noxious, or both inputs to a restricted area within S1 suggests that inputs from NS, WDR, and $\mathrm{NN}$ neurons are not segregated into anatomically distinct regions. Thus, if $\mathrm{S} 1$ cortex is involved in the discrimination of the locations of noxious stimuli, then it is not dependent on a continuous somatotopically organized map of nociceptive neurons.

The strong convergence of spinal and lemniscal afferents to the VPL (Ma et al., 1987) and the close correspondence between afferents and efferents within the VPL-S1 network (Deschênes et al., 1998; Jones 2002) (Fig. 2) suggest that corticofugal output could modulate both innocuous and noxious inputs. Moreover, there appears to be little if any interaction between VPL cells, as witnessed by the absence of local interneurons and lack of dendrodendritic synapses and local axon collaterals within the rat VPL (Harris and Hendrickson, 1987).

Corticothalamic feedback is a major component of thalamocortical circuitry, as shown by the greater number of fibers projecting back from the cortex to the thalamus compared with the number going in a forward direction from thalamus to cortex (Liu et al., 1995; Deschênes et al., 1998; Jones, 2002; Salt, 2002). Although there have been several studies of the corticothalamic projection from S1 in the rat, most detailed studies have been performed in the thalamocortical zones of the whisker representation (Chmielowska et al., 1989). As shown in Figure 2, the S1 cortices that contained the most dense VPL afferents also contained the largest number of retrogradely labeled cells in the deep layers, and these showed a distribution that paralleled that of the layer IV thalamic afferents. It follows the general principle of there being a well circumscribed, precise, thalamocortical reciprocity. The precise identification of the area, within S1, of termination of functionally identified VPL recipient zones of lemniscal and noxious inputs from the hindpaw was necessary to clarify the extent and organization of this feedback system. Also, this was a prerequisite necessary for a more precise pharmacological manipulation of corticofugal output.

Simultaneous extracellular recordings in S1 and VPL showed that top-down influences from the S1 cortex modulate cutaneous inputs. We investigated the role of GABA and glutamate because corticofugal neurons that modulate somatosensory inputs receive inputs from these neurotransmitters (Montagne-Clavel and Oliveras, 1997; Ghazanfar et al., 2001; Salt, 2002; Jasmin et al., 2003). 
Corticofugal influences on sensory processing in VPL: a link for bottom-up and top-down processing

Previous findings (Deschênes et al., 1998; Jones, 2002) showed that a major, direct source of descending input to ventrobasal thalamic neurons comes from neurons with cell bodies located in layers V-VI of S1. These corticothalamic neurons exert both direct excitatory and indirect inhibitory influences on relay cells, and the resultant balance of excitation and inhibition is thought to influence the activity patterns and sensory response properties of relay neurons (Deschênes et al., 1998; Jones, 2002; Suga and Ma, 2003). Former studies in the somatosensory system have shown that cortical inactivation mainly depresses innocuous-evoked thalamic responses (Yuan et al., 1986; Diamond et al., 1992). More recent studies demonstrated that S1 can selectively modulate thalamic spatial responses through specific excitatory or inhibitory mechanisms that either sharpen or enlarge thalamic receptive fields (Ergenzinger et al., 1998; Ghazanfar et al., 2001; Temereanca and Simons, 2004).

Our findings show that $\mathrm{S} 1$ is also able to selectively modulate different somatosensory submodalities. In our experiments, no significant changes were observed in thalamic thresholds for activation, background activity, and afterdischarges. S1 activity could contribute to detect innocuous and noxious cutaneous inputs through specific tuning mechanisms acting simultaneously in the three functional types of cells within the VPL. NS and WDR neurons in the VPL receive direct, spinothalamic excitatory nociceptive inputs that presumably, in turn, activate a predominantly excitatory feedback from S1. Although our experimental conditions do not allow us to exclude additional, pyramidal modulation, we assume that this facilitation is probably mediated via direct, corticothalamic influences. This is supported by our observations that corticofugal modulation driven by noxious inputs is net excitatory, and the literature showing that corticothalamic fibers contact distal dendrites of VPL cells via glutamatergic synapses and provide excitatory influences mediated by both AMPA and NMDA receptors at this level (Jones, 2002; Salt, 2002). Enhancement of corticofugal output by bicuculline also enhanced the nociceptive responses, although no significant enhancement of NN responses were observed. The reason for this difference is not clear but might be attributable to a more selective influence on a subpopulation of corticothalamic neurons. It is possible that VPL neurons are normally under strong $\mathrm{GABA}_{\mathrm{A}}$-mediated corticofugal control that cannot be further increased by increasing GABA activity by bicuculline but can be attenuated by muscimol. Conversely, the consistent facilitatory effects on brushing-evoked responses, $\mathrm{S} 1$ microinjections of a $\mathrm{GABA}_{\mathrm{A}}$ agonist, the lack of effects of a $\mathrm{GABA}_{\mathrm{A}}$ antagonist, and the mixed effects of DLH
B

NS cell $(n=10)$

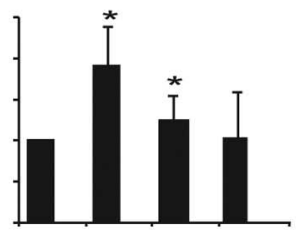

WDR cell $(n=37)$

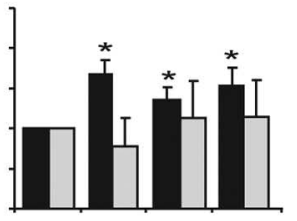

NN cell $(n=11)$

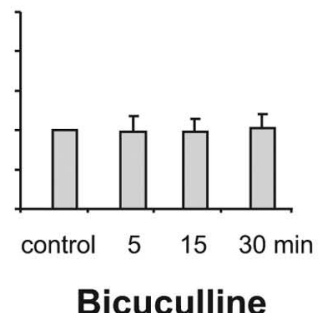

NN cell $(n=16)$

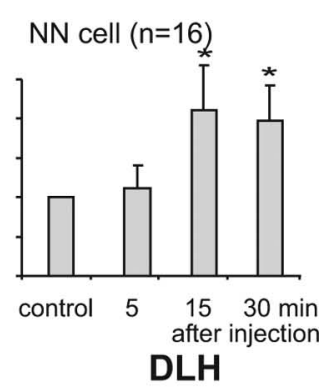

- noxious heat $\square$ brush

NS cell $(n=6)$
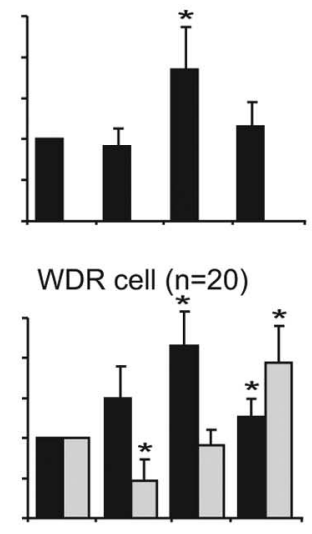

WDR cell $(n=20)$

(1)

Figure 6. Summary of the experiments during which the effects on the responses of VPL neurons, of microinjections of muscimol, bicuculline, or DLH in layer V-VI of the S1 cortex were studied. Results are expressed as percentages of control responses

Table 1. Effects on the responses of VPL neurons of microinjections within layer V-VI of the S1 cortex

\begin{tabular}{|c|c|c|c|c|}
\hline & \multirow{2}{*}{$\begin{array}{l}\text { NS } \\
\text { Thermal stim }\end{array}$} & \multicolumn{2}{|l|}{ WDR } & \multirow{2}{*}{$\begin{array}{l}\text { NN } \\
\text { Brush }\end{array}$} \\
\hline & & Thermal stim & Brush & \\
\hline $\begin{array}{l}\text { Muscimol } \\
\text { Bicuculline } \\
\text { DLH }\end{array}$ & $\begin{array}{l}-73 \pm 12 \%^{*} \\
+91 \pm 73 \%^{*, * *} \\
+80 \pm 26 \%^{*}\end{array}$ & $\begin{array}{l}-37 \pm 24 \%^{*} \\
+54 \pm 17 \%^{*, * *} \\
+125 \pm 46 \%^{*}\end{array}$ & $\begin{array}{l}+45 \pm 42 \% * \\
\text { No effect } \\
-75 \pm 16 \% * \text { and then } \\
+90 \pm 44 \%^{*}\end{array}$ & $\begin{array}{l}+68 \pm 47 \% * \\
\text { No effect } \\
+107 \pm 70 \% *\end{array}$ \\
\hline
\end{tabular}

Results are expressed as percentage of control responses before the microinjection. - , Depression; + , enhancement. ${ }^{*} p<0.05$ compared with control (ANOVA and Student's $t$ test). ${ }^{* *} p<0.05$ for difference with muscimol (Mann-Whitney $U$ test).

argue for the existence of a different, predominant inhibitory, corticofugal mechanism elicited by innocuous inputs. The inhibition of corticofugal output by muscimol may affect the lateral inhibition through monosynaptic glutamatergic inputs to the NRT from layer VI corticothalamic cells (Steriade, 2001; Pinault, 2004), pyramidal influences acting on the gracilis nuclei (Mariño et al., 1999; Malmierca and Nuñez, 2004), or the spinal cord. An increase in tactile responses indicates that such peripheral stimuli are normally depressed by the NRT or pyramidal influences. It seems interesting to investigate whether similar mechanisms are brought into play in parallel targets of the rat spinothalamic system, such as those terminating in the posterior group (Gauriau and Bernard, 2004).

\section{Implications for pain perception in human beings}

Although thalamic relay cells of all species show a predominant input from the cerebral cortex (Jones, 2002), it is important to emphasize the existence of strong differences between primate and rodent thalamus. Rodents lack the intrinsic GABAergic circuitry, which constitutes $\sim 25 \%$ of the population of the somato- 
sensory thalamus and probably plays an additional, important role in pain modulation in primates (Ralston, 2005).

Previous human brain imaging studies revealed that noxious heat applied to regions of the forearm elicited activation, a decrease, or a lack of modification of activity in the S1 cortex (Jones et al., 1991; Talbot et al., 1991; Apkarian et al., 1992). Recent studies showed that these discrepancies were mostly attributable to the fact that $\mathrm{S} 1$ activation by either tactile or painful stimuli is strongly modulated by cognitive factors, including attention, that modify somatosensory perception (Meyer et al., 1991; Rainville et al., 1997; Hofbauer et al., 2001; Kulkarni et al., 2005). Moreover, experimental manipulations specifically directed toward changing the perceived intensity, location, but not the unpleasantness of pain evoked by a noxious stimulus, significantly modulated activity in S1 (Rainville et al., 1997; Hofbauer et al., 2001; Kulkarni et al., 2005). Although it is still unknown how the cortex "knows" that inputs are nociceptive or innocuous, these findings suggest that peripheral mechanisms related to intracortical processing strongly modulate pain (Bushnell et al., 1999; Duncan and Albanese, 2003). However, this does not exclude the participation of endogenous processes, independent of peripheral events.

Moreover, part of the modulation observed in human studies may be subserved by corticofugal mechanisms driven by peripheral stimuli that are modality specific, such as those described here. Consistent with this possibility is the observation that nociceptive input to S1 can modulate tactile perception, as shown by the observations that noxious heat is able to reduce the intrinsic optical imaging signal in S1 evoked by innocuous mechanical stimulation of the skin (Tommerdahl et al., 1996). Furthermore, psychophysical studies have shown that the presence of pain reduces tactile perception of stimuli applied as in the present study, in the vicinity of the noxious stimulus. This phenomenon was described as a "touch gate" and could not be attributed to nonspecific changes elicited by generalized arousal or attentional reactions (Apkarian et al., 1994). These mechanisms could also explain previous clinical observations showing that chronic pain relief resulted in sharpening of tactile perception (Nathan, 1960).

Together, human and animal studies indicate that stimulusevoked responses of S1 corticofugal neurons can contribute to somatosensory processing by selecting thalamic responses to preferred versus nonpreferred inputs, in a modality-specific manner. In conjunction with mechanisms underlying topographic response sharpening, heightened activity in corticofugal S1 neurons may create a circumscribed zone of enhanced activity within the thalamocortical loop that contributes to perceive tactile and painful sensations. The existence of such a focal somatotopic organization has been suggested recently in humans by lesion (Ploner et al., 1999), microstimulation (Lenz et al., 2004), and electrophysiological (Kakigi et al., 2005, references therein) studies.

\section{References}

Albe-Fessard D, Berkley KJ, Kruger L, Ralston HJ, Willis WD (1985) Diencephalic mechanisms of pain sensation. Brain Res Rev 9:217-296.

Apkarian AV, Stea RA, Manglos SH, Szeverenyi NM, King RB, Thomas FD (1992) Persistent pain inhibits contralateral somatosensory cortical activity in humans. Neurosci Lett 140:141-147.

Apkarian AV, Stea RA, Bolanowski SJ (1994) Heat-induced pain diminishes vibrotactile perception: a touch gate. Somatosens Mot Res 11:259-267.

Bushnell MC, Duncan GH, Hofbauer RK, Ha B, Chen JI, Carrier B (1999) Pain perception: is there a role for primary somatosensory cortex? Proc Natl Acad Sci USA 96:7705-7709.

Chmielowska J, Carvell GE, Simons DJ (1989) Spatial organization of thalamocortical and corticothalamic projection systems in the rat SmI barrel cortex. J Comp Neurol 285:325-338.

Craig AD (2003) Pain mechanisms: labeled lines versus convergence in central processing. Annu Rev Neurosci 26:1-30.

Deschênes M, Veinante P, Zhang ZW (1998) The organization of corticothalamic projections: reciprocity versus parity. Brain Res Rev 28:286-308.

Diamond ME, Armstrong-James M, Budway MJ, Ebner FF (1992) Somatic sensory responses in the rostral sector of the posterior group (POm) and the ventral posterior medial nucleus (VPM) of the rat thalamus: dependence on the barrel cortex. J Comp Neurol 319:66-84.

Duncan GH, Albanese MC (2003) Is there a role for the parietal lobes in the perception of pain? Adv Neurol 93:69-86.

Eckhorn R, Thomas U (1993) A new method for the insertion of multiple microprobes into neural and muscular tissue, including fiber electrodes, fine wires, needles and microsensors. J Neurosci Methods 49:175-179.

Ergenzinger ER, Glasier MM, Hahm JO, Pons TP (1998) Cortically induced thalamic plasticity in the primate somatosensory system. Nat Neurosci $1: 226-229$.

Gauriau C, Bernard JF (2004) A comparative reappraisal of projections from the superficial laminae of the dorsal horn in the rat: the forebrain. J Comp Neurol 468:24-56.

Ghazanfar AA, Krupa DJ, Nicolelis MAL (2001) Role of cortical feedback in the receptive field structure and nonlinear response properties of somatosensory thalamic neurons. Exp Brain Res 141:88-100.

Ghosh S, Murray GM, Turman AB, Rowe MJ (1994) Corticothalamic influences on transmission of tactile information in the ventroposterolateral thalamus of the cat: effect of reversible inactivation of somatosensory cortical areas I and II. Exp Brain Res 100:276-286.

Guilbaud G (1985) Thalamic nociceptive systems. Philos Trans Soc Lond B Biol Sci 308:339-345.

Harris RM (1986) Morphology of physiologically identified thalamocortical relay neurons in the rat ventrobasal thalamus. J Comp Neurol 251:491-505.

Harris RM, Hendrickson AE (1987) Local circuit neurons in the rat ventrobasal thalamus: a GABA immunocytochemical study. Neuroscience $1: 229-236$.

Hofbauer RK, Rainville P, Duncan GH, Bushnell MC (2001) Cortical representation of the sensory dimension of pain. J Neurophysiol 86:402-411.

Jasmin L, Rabkin SD, Granato A, Boudah A, Ohara PT (2003) Analgesia and hyperalgesia from GABA-mediated modulation of the cerebral cortex. Nature 424:316-320.

Jones AKP, Brown WD, Friston KJ, Qi LY, Frackowiak RSJ (1991) Cortical and subcortical localization of response to pain in man using positron emission tomography. Proc R Soc Lond B Biol Sci 244:39-44.

Jones EG (2002) Thalamic circuitry and thalamocortical synchrony. Philos Trans R Soc Lond B Biol Sci 357:1659-1673.

Kakigi R, Inui K, Tamura Y (2005) Electrophysiological studies on human pain perception. Clin Neurophysiol 116:743-763.

Krupa DJ, Ghazanfar AA, Nicolelis MAL (1999) Immediate thalamic sensory plasticity depends on corticothalamic feedback. Proc Natl Acad Sci USA 96:8200-8205.

Kulkarni B, Bentley DE, Elliott R, Youell P, Watson A, Derbyshire SWG, Frackowiak RSJ, Friston KJ, Jones AKP (2005) Attention to pain localization and unpleasantness discriminates the functions of the medial and lateral pain systems. Eur J Neurosci 21:3133-3142.

Lenz FA, Ohara S, Gracely RH, Dougherty PM, Patel SH (2004) Pain encoding in the human forebrain: binary and analog exteroceptive channels. J Neurosci 24:6540-6544.

Liu XB, Honda CN, Jones EG (1995) Distribution of four types of synapse on physiologically identified relay neurons in the ventral posterior thalamic nucleus of the cat. J Comp Neurol 352:69-91.

Ma W, Peschanski M, Ralston HJ (1987) The differential synaptic organization of the spinal and lemniscal projections to the ventrobasal complex of the rat thalamus. Evidence for convergence of the two systems upon single thalamic neurons. Neuroscience 3:925-934.

Malmierca E, Nuñez A (2004) Primary somatosensory cortex modulation of tactile responses in nucleus gracilis cells of rats. Eur J Neurosci 19:1572-1580.

Mariño J, Martinez L, Canedo A (1999) Sensorimotor integration at the dorsal column nuclei. News Physiol Sci 14:231-237.

Meyer E, Ferguson SS, Zatorre RJ, Alivisatos B, Marrett S, Evans AC, Hakim AM (1991) Attention modulates somatosensory cerebral blood flow re- 
sponse to vibrotactile stimulation as measured by positron emission tomography. Ann Neurol 29:440-443.

Monconduit L, Villanueva L (2005) The lateral ventromedial thalamic nucleus spreads nociceptive signals from the whole body surface to layer I of the frontal cortex. Eur J Neurosc 21:3395-3402.

Monconduit L, Bourgeais L, Bernard JF, Le Bars D, Villanueva L (1999) Ventromedial thalamic neurons convey nociceptive signals from the whole body surface to the dorsolateral neocortex. J Neurosci 19:9063-9072.

Monconduit L, Lopez-Avila A, Molat JL, Chalus M, Villanueva L (2005) Stimulus-driven, feedback mechanisms from the primary somatosensory cortex selectively modulate innocuous and noxious inputs in the rat ventrobasal thalamus. Soc Neurosci Abstr 31:983.2.

Montagne-Clavel J, Oliveras JL (1997) Cholinergic modulation of the picrotoxin-induced electrocorticographical events and behavioral "painlike" symptoms at somatomotor cortical level in the rat. Exp Brain Res 117:362-368.

Nathan PW (1960) Improvement in cutaneous sensibility associated with relief of pain. J Neurol Neurosurg Psychiatry 23:202-206.

Nicolelis MA, Ghazanfar AA, Faggin BM, Votaw S, Oliveira LMO (1997) Reconstructing the engram: simultaneous, multisite, many single neuron recordings. Neuron 18:529-537.

Paxinos G, Watson C (1997) The rat brain in stereotaxic coordinates, Ed 3. New York: Academic.

Peschanski M, Lam Lee C, Ralston HJ (1984) The structural organization of the ventrobasal complex of the rat as revealed by the analysis of physiologically characterized neurons injected intracellularly with horseradish peroxidase. Brain Res 297:63-74.

Pilowsky PM, Makeham J (2001) Juxtacellular labeling of identified neurons: kiss the cells and make them dye. J Comp Neurol 433:1-3.

Pinault D (1996) A novel single-cell staining procedure performed in vivo under electrophysiological control: morpho-functional features of juxtacellularly labelled thalamic cells and other central neurons with biocytin or Neurobiotin. J Neurosci Methods 65:113-136.

Pinault D (2004) The thalamic reticular nucleus: structure, function and concept. Brain Res Rev 46:1-31.

Ploner M, Freund HJ, Schnitzler A (1999) Pain affect without pain sensation in a patient with a postcentral lesion. Pain 81:211-214.

Rainville P, Duncan GH, Price DD, Carrier B, Bushnell MC (1997) Pain affect encoded in human anterior cingulate but not somatosensory cortex. Science 277:968-971.

Ralston HJ (2005) Pain and the primate thalamus. Prog Brain Res 149:1-10.

Rauschecker JP (1998) Cortical control of the thalamus: top-down processing and plasticity. Nat Neurosci 1:179-180.

Salt TE (2002) Glutamate receptor functions in sensory relay in the thalamus. Philos Trans Soc Lond B Biol Sci 357:1759-1766.

Shi T, Apkarian AV (1995) Morphology of thalamocortical neurons projecting to the primary somatosensory cortex and their relationship to spinothalamic terminals in the squirrel monkey. J Comp Neurol 361:1-24.

Steriade M (2001) The GABAergic reticular nucleus: a preferential target of corticothalamic projections. Proc Natl Acad Sci USA 98:3625-3627.

Suga N, MaX (2003) Multiparametric corticofugal modulation and plasticity in the auditory system. Nat Rev Neurosci 4:783-794.

Talbot JD, Marrett S, Evans AC, Meyer E, Bushnell MC, Duncan GH (1991) Multiple representations of pain in human cerebral cortex. Science 251:1355-1358.

Temereanca S, Simons DJ (2004) Functional topography of corticothalamic feedback enhances thalamic spatial response tuning in the somatosensory whisker/barrel system. Neuron 41:639-651.

Tommerdahl M, Delemos KA, Vierck CJ, Favorov OV, Whitsel BL (1996) Anterior parietal cortical response to tactile and skin-heating stimuli applied to the same skin site. J Neurophysiol 75:2662-2670.

Villanueva L, Le Bars D (1993) Computer-assisted reconstruction of axonal arborizations anterogradely labelled with the Phaseolus vulgaris leucoagglutinin technique. J Neurosci Methods 50:217-224.

Weksler B, Ng B, Lenert J, Burt M (1994) A simplified method for endotracheal intubation in the rat. J Appl Physiol 76:1823-1825.

Willis WD, Zhang X, Honda CN, Giesler GJ (2002) A critical review of the role of the proposed VMpo nucleus in pain. J Pain 3:79-94.

Yuan B, Morrow TJ, Casey K (1986) Corticofugal influences of S1 Cortex on ventrobasal thalamic neurons in the awake rat. J Neurosci 6:3611-3617.

Zhang X, Davidson S, Giesler GJ (2006) Thermally identified subgroups of marginal zone neurons project to distinct regions of the ventral posterior lateral nucleus in rats. J Neurosci 26:5215-5223.

Zimmermann M (1983) Ethical guidelines for investigations of experimental pain in conscious animals. Pain 16:109-110. 